\title{
Analysis Methods for Aerodynamic Instability Detection on a Multistage Axial Compressor
}

\author{
Baofeng Tu $\mathbb{D},{ }^{1}$ Xinyu Zhang $\mathbb{D},{ }^{1}$ Jun $\mathrm{Hu}^{1},{ }^{1}$ Ming Zhong, ${ }^{2}$ and Bing Xiong ${ }^{2}$ \\ ${ }^{1}$ Jiangsu Province Key Laboratory of Aerospace Power System, College of Energy and Power Engineering, Nanjing University of \\ Aeronautics and Astronautics, No. 29 Yudao Street, Nanjing 210016, China \\ ${ }^{2}$ Sichuan Gas Turbine Research Establishment, Aero Engine Corporation of China, Mianyang, Sichuan 621700, China
}

Correspondence should be addressed to Baofeng Tu; tubaofeng@126.com

Received 13 May 2020; Revised 28 August 2020; Accepted 29 July 2021; Published 18 August 2021

Academic Editor: Jun-Wei Li

Copyright (c) 2021 Baofeng Tu et al. This is an open access article distributed under the Creative Commons Attribution License, which permits unrestricted use, distribution, and reproduction in any medium, provided the original work is properly cited.

In order to detect the aerodynamic instability of a multistage axial compressor more accurately and earlier, the harmonic Fourier mean amplitude analysis method and heterotopic variance analysis method are developed. The dynamic instability prediction performance of the two methods is studied on a low-speed and a high-speed two-stage axial compressor. The harmonic Fourier mean amplitude analysis method is suitable for predicting the aerodynamic instability of a multistage axial compressor in the form of a rotating stall. Compared with the traditional harmonic Fourier analysis methods, the harmonic Fourier mean amplitude analysis method can capture the detail of the pressure signal more accurately and it can effectively prevent instability misjudgment. The heterotopic variance analysis method is developed based on the conventional variance analysis method, and it can be used to distinguish whether the compressor is in the rotating stall or the surge state. The heterotopic variance analysis method can predict the aerodynamic instability ahead of the harmonic Fourier mean amplitude analysis method, and fewer circumferential measuring points were employed. The layout of the measuring points also influences the detection of the aerodynamic instability of the compressor. The aerodynamic instability of the high-speed axial compressor can be predicted earlier by employing measuring points at the compressor outlet.

\section{Introduction}

As the power unit of an aircraft, the aeroengine may enter various aerodynamic instability states (rotating stall and surge), thus inducing thrust reduction, extra fuel consumption, and critical problems. Once the aerodynamic instability is likely to or has already appeared, measures such as adjusting the fuel mass flow rate, the turbine inlet guide area, and the installation angle of the inlet guide are often taken to stabilize the engine down to the stable working condition. If the working state of the aeroengine is misadjusted due to an unreliable aerodynamic instability detection method, the performance of the engine would be reduced suddenly. To avoid potential flight safety risks, accurate and early detection of the aerodynamic instability of the aeroengine is necessary.
Generally, the common working line and the stability boundary are measured during the aeroengine test to determine whether the stability margin meets the design requirements. The working condition of the engine can be changed from the stable state to the unstable state by fuel step, nozzle area closing, adjustment of the turbine guide installation angle, and injection of gas from the highpressure compressor outlet.

In the experiment of determining the stability boundary of the compressor, the transition from the aerodynamic stable state to the aerodynamically unstable state is realized by controlling the throttle opening. The instability detection device in the test bench is used to judge whether the compressor is unstable. Once instability occurs in the compressor, the power of the compressor motor and the 
valve opening area must be quickly adjusted to make the compressor retreat from the instability state in time to prevent damage to the compressor.

Early and accurate aerodynamic instability detection methods are urgently demanded for an aeroengine no matter whether it is in service or in the course of development. Many scholars have carried out relevant research in this field, and the detection of aerodynamic instability based on prestall disturbances has become a research hotspot.

In 1986, Jackson [1] first proposed the prestall disturbance of modal wave through a single-stage axial compressor experiment at Cambridge University, and then, McDougall [2], Garnier et al. [3], Day [4-6], Tryfonidis et al. [7], and Tu et al. [8] found the phenomenon of the modal wave on several low-speed and high-speed axial compressors. The modal wave was a kind of low amplitude disturbance, and the wavelength took the compressor circumference as the characteristic scale. The modal wave propagated between 20 and 50 percent of rotor speed in the circumferential direction, and it generally appeared in the first 10 to 100 rotor rotation cycles before evolving into the stall. In 1993, Day [4] conducted an experimental study and found that a sharp pulse disturbance signal would generate in the compressor before stall. The disturbance signal, also known as the "spike," had a large amplitude, and the wavelength was characterized by the length of the blade passage. The spike type prestall disturbance propagated at 70 to 80 percent of design rotor speed in the circumferential direction. When the disturbance evolved into the complete rotating stall, its speed dropped to 20 to 50 percent of the design rotor speed. The time interval between the occurrence of the spike type prestall disturbance and the formation of the rotating stall or the surge was no more than 5 rotor rotation cycles. Silkowski [9] confirmed the existence of the disturbance signal through experiments. The stall inception process was more complex in a multistage high-pressure axial compressor. Day found that the spike type prestall disturbance appeared before the stall at 60 percent of the design rotor speed, whereas modal wave appeared before the stall at 80 percent of the design rotor speed. The fluctuation of the spike type prestall disturbance sometimes could be observed at higher rotor speed, sometimes could not be observed [5].

$\mathrm{Li}$ and $\mathrm{Du}[10-13]$ correlated the spike type prestall disturbance with the unsteady tip leakage flow of the rotor. In order to capture the evolutionary process of the circumferential propagation of the tip leakage flow, a group of time-resolved pressure transducers was arranged on the casing along the circumferential and chord-wise spatial direction. Results showed that the circumferential propagation dominated by the unsteady tip leakage flow existed and occurred only after the emergence of the unsteady tip leakage flow in the throttling process. The propagating speed and the scale of disturbance gradually increase until the stage of transition to stall inception.

Li et al. $[14,15]$ investigated the aerodynamic instability evolution of a transonic axial compressor. In the condition of low rotor speeds, a disturbance appeared in the rotor tip region and then developed into the rotating stall. In the condition of high rotor speeds, a low-frequency disturbance in the hub region caused the compressor to enter the instability state. The new type of compressor instability named "partial surge" which arises at high rotor speed was initiated by a low-frequency axisymmetric disturbance at the hub.

Rzadkowski et al. $[16,17]$ carried out a Fourier analysis to investigate the instability process in a 3.5-stage compressor. It was found that partial blocking at the engine inlet caused low-frequency harmonics to affect not only the first and the second rotor blade stages but also the third stage, with only slightly smaller amplitude values. A dynamic multistage analysis was also carried out in their following work, and advantageous suggestions in regard to the blade failure were put forward.

In the early study of prestall disturbances, researchers observed the existence of these small disturbances from the original data and simple filter processing and then used different data processing methods in order to observe the existence of prestall disturbances in advance.

At present, the commonly used aerodynamic instability detection methods can be mainly divided into time-domain analysis method [1-9], frequency-domain analysis method [10-17], bifurcation method, and chaos-based analysis method [18-22].

The time-domain analysis was to analyze the pressure or velocity signal fluctuation with time in a multistage axial compressor. Filtering method, variance method, average difference method, correlation analysis method, and short-time energy method were used to analyze the dynamic changes of the amplitude, mean value, and variance of the pressure or velocity signal.

The frequency-domain analysis method judged the main impacting component by frequency and the corresponding amplitude of the pressure or velocity signal. The commonly used frequency-domain analysis methods include the fast Fourier transform method, the short-time Fourier transform method, the harmonic Fourier transform method, the power spectral density method, the traveling wave energy method, and the wavelet analysis method.

The aerodynamic instability prediction method based on chaos theory focused on the pressure or velocity signal time series of the compressor, and it can be subdivided into the correlation integral method, the structure-function method, the chaos attractor, and the correlation dimension method.

However, prestall disturbances were sometimes observed in high-speed axial compressors, because linear modal waves did not necessarily exist while spikes may originate at a place far from the probes, whose signals have been flattened when detected. Moreover, the prestall disturbances are so close to the stall inception that the signals are hard to be distinguished from each other. Therefore, it is necessary to develop a suitable method, which can not only determine that the engine is to lose stability in advance in the presence of the prestall disturbances but also accurately and timely determine that the engine has lost stability in the absence of the prestall disturbances.

The internal flow field of a multistage axial compressor is natively unsteady. The fluctuation amplitude of the aerodynamic parameter in the steady-state is smaller than that in 
the rotating stall or surge state. The emergence of two kinds of prestall disturbances, the modal wave, and the spike will increase the fluctuation range of flow parameters. Therefore, the aerodynamic instability evolution process in a compressor can be considered as the process where the fluctuating amplitude of pressure, velocity, and other aerodynamic parameters increase rapidly, no matter whether there are prestall disturbances or not.

Based on the harmonic Fourier method and the variance analysis method, two new methods to detect the aerodynamic instability of a multistage compressor are developed in the present work, which performs well in predicting aerodynamic instability at the low-speed and high-speed compressor.

\section{Methodology}

2.1. Harmonic Fourier Mean Amplitude Analysis Method. The harmonic Fourier analysis method is to expand the periodic function of time into the sum of infinite sine and cosine functions that can fit the original signal. The harmonic Fourier transform can balance the circumferential nonuniformity of the sampled signal. The results of the harmonic Fourier mean amplitude analysis in a period of time are calculated by the following formula:

$$
\begin{aligned}
& a(t)=\sum_{\mathrm{i}=1}^{n}\left\{P(t, i) \cdot \cos \left(2 \pi \frac{i-1}{n}\right)\right\}, \\
& b(t)=\sum_{\mathrm{i}=1}^{n}\left\{P(t, i) \cdot \sin \left(2 \pi \frac{i-1}{n}\right)\right\}, \\
& A(t)=2 \cdot \sqrt{\left(a(t)^{2}+b(t)^{2}\right)} \\
& A(t)=\frac{1}{T} \int_{t-T}^{t} A(t) d t
\end{aligned}
$$

where $P(t, i)$ is the pressure signal measured by $i$ dynamic pressure sensors at time $t$ and $n$ is the number of the circumferential dynamic pressure measuring point. $A(t)$ represents the vibration amplitude of the sinusoidal harmonic at time $t$. $A \overline{A(t)}$ is the mean value of the vibration amplitude of the sinusoidal harmonic, and the time window length before time $t$ is equal to $T$.

2.2. Heterotopic Variance Analysis Method. The conventional variance analysis method is used to judge the strength of the dynamic pressure signal fluctuation in a period of time. If the amplitude of the signal suddenly increases and exceeds a certain threshold, the compressor was considered to be unstable. Based on the variance analysis method, the heterotopic variance analysis method has developed the capability to distinguish whether the compressor is in the rotating stall or the surge state. Two measuring points are arranged in different circumferential positions to measure the dynamic pressure signal. The signal is then analyzed with a time window of $T$. Two heterotopic variance analysis

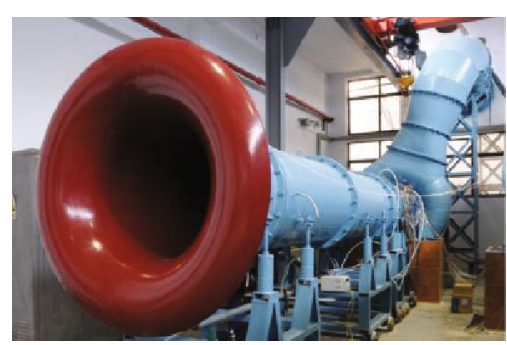

FIgURE 1: Test bench of the low-speed axial compressor.

parameters, $\sigma(t)_{1}{ }^{2}$ and $\sigma(t)_{2}{ }^{2}$, are calculated by formula (2) and formula (3), respectively.

$$
\sigma(t)_{1}^{2}=\frac{1}{T} \times \sum_{i=1}^{N}\left\{P_{1}(t, i)-P_{2}(t, i)-\frac{1}{N} \times \sum_{i=1}^{N}\left(P_{1}(t, i)-P_{2}(t, i)\right)\right\}^{2},
$$

$\sigma(t)_{2}{ }^{2}=\frac{1}{T} \times \sum_{i=1}^{N}\left\{P_{1}(t, i)+P_{2}(t, i)-\frac{1}{N} \times \sum_{i=1}^{N}\left(P_{1}(t, i)+P_{2}(t, i)\right)\right\}^{2}$.

A surge is a kind of unstable flow state with low-energy fluid oscillating back and forth along the axial direction of the compressor. When the compressor enters the surge state, the measuring points at the different circumferential positions and the same axial position sense almost the same pressure changes. In this case, $\sigma(t)_{1}{ }^{2}$ is approximately equal to zero, whereas $\sigma(t)_{2}{ }^{2}$ can be very large.

A rotating stall is a kind of flow state with low-energy fluid rotating along the circumferential direction of the compressor. When the compressor enters the rotating stall state, the pressure sensed at different circumferential positions and the same axial position is different, so the difference between the values of $\sigma(t)_{1}{ }^{2}$ and $\sigma(t)_{2}{ }^{2}$ is not obvious, and both of the parameters are relatively large.

\section{Experiment Equipment}

3.1. Two-Stage Low-Speed Axial Compressor. The axial compressor test bench was composed of a bell mouth, an inlet pipe, a two-stage axial compressor, a volute, an exhaust pipe, a throttle valve, a silencing tower, and a motor (Figure 1). An electric throttle valve was installed in the exhaust pipe to regulate the airflow, and a $200 \mathrm{~kW}$ motor was used to drive the rotor and adjust the rotor speed. The detailed design data of the compressor are presented in Table 1.

In the low-speed axial compressor test, six dynamic total pressure probes embedded with Kulite dynamic sensors and LMS SCADA III dynamic pressure measuring instrument were used. Kulite CQ-140-350M type highfrequency response microdifferential pressure sensors were selected, and they were directly embedded near the measuring point to ensure the high-frequency response of the probe. All of the dynamic total pressure sensors measure the total 
TABLE 1: Design parameters of the two-stage low-speed axial compressor.

\begin{tabular}{|c|c|c|c|c|}
\hline Parameter & \multicolumn{4}{|c|}{ Value } \\
\hline Outside diameter $/ \mathrm{mm}$ & \multicolumn{4}{|c|}{900} \\
\hline Hub-tip ratio & \multicolumn{4}{|c|}{0.6} \\
\hline Nominal speed/(r/min) & \multicolumn{4}{|c|}{1500} \\
\hline Total pressure ratio & \multicolumn{4}{|c|}{1.035} \\
\hline Efficiency & \multicolumn{4}{|c|}{0.88} \\
\hline Mass flow/(kg/s) & \multicolumn{4}{|c|}{25} \\
\hline Row & First rotor & First stator & Second rotor & Second stator \\
\hline Blade profile & \multicolumn{4}{|c|}{ NACA-65-010 } \\
\hline Chord length/mm & 122 & 106 & 130 & 117 \\
\hline Blade number & 19 & 22 & 18 & 20 \\
\hline Radial clearance $/ \mathrm{mm}$ & 1.5 & 0 & 1.2 & 0 \\
\hline
\end{tabular}

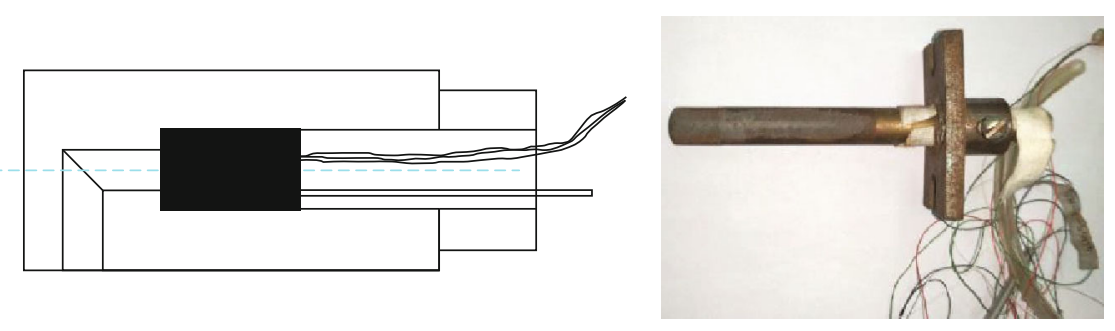

Figure 2: Structure diagram of the dynamic total pressure probe.

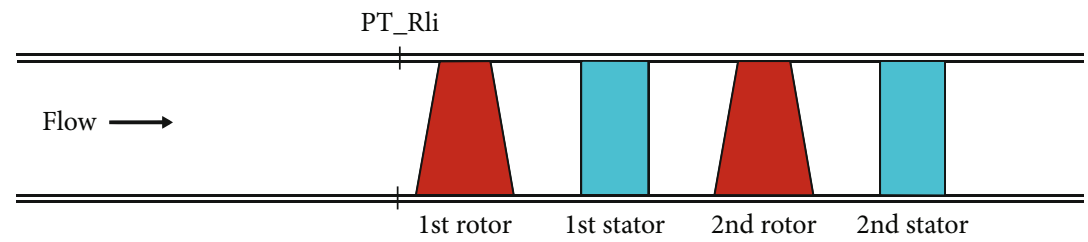

FIGURE 3: Sensor arrangement sketch of the low-speed axial compressor.

pressure at the tip area about $10 \mathrm{~mm}$ from the outer casing, and the maximum response frequency was $300 \mathrm{kHz}$. The dynamic-state data acquisition system allowed online monitoring of the compressor and could provide measurements of 32 channels with a sampling rate of $200 \mathrm{kHz}$ per sensor on a 16-bit resolution A/D converter. The sampling frequency of the dynamic pressure was $4096 \mathrm{~Hz}$, which was enough to catch the stall cell. Dynamic pressure probes were approximately $100 \%$ chord length upstream of the first-stage rotor, and the probes were placed at $90 \%$ blade height in the radial direction. When the probe was arranged too far upstream the rotor leading edge, the prestall disturbance signal might not be detected, whereas the disturbance potential of the rotor leading edge affected the measurement, and the wake of the probe interfere the flow between the compressor blades when the probe was arranged too close. The six measuring points were evenly distributed along the circumference (Figure 2). The arrangement of the sensors and the measuring points of the low-speed axial compressor are presented in Figures 3 and 4, respectively.

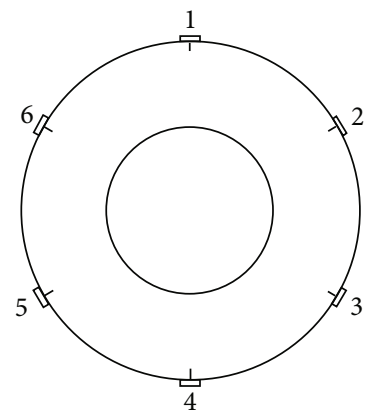

FIgURE 4: Measurement points sketch of the low-speed axial compressor.

3.2. Two-Stage High-Speed Axial Compressor. The instability dynamic process of a type of two-stage high-speed axial compressor was studied. The design speed of the compressor was $18000 \mathrm{r} / \mathrm{min}$. The type of measuring tools was the same as 
TABle 2: Dynamic test parameters of the two-stage high-speed compressor.

\begin{tabular}{lcc}
\hline Number & Test location & Measuring point mark \\
\hline 1 & Inlet of R1 at $0^{\circ}$ & PS_R1i_1 \\
2 & Inlet of R1 at $45^{\circ}$ & PS_R1i_2 \\
3 & Inlet of R1 at $90^{\circ}$ & PS_R1i_3 \\
4 & Inlet of R1 at $135^{\circ}$ & PS_R1i_4 \\
5 & Inlet of R1 at $180^{\circ}$ & PS_R1i_5 \\
6 & Inlet of R1 at $225^{\circ}$ & PS_R1i_6 \\
7 & Inlet of R1 at $270^{\circ}$ & PS_R1i_7 \\
8 & Inlet of R1 at $315^{\circ}$ & PS_R1i_8 \\
9 & Inlet of R2 at $90^{\circ}$ & PS_R2i_1 \\
10 & Inlet of R2 at $180^{\circ}$ & PS_R2i_2 \\
11 & Outlet of S2 at $90^{\circ}$ & PS_S2o_1 \\
12 & Outlet of S2 at $180^{\circ}$ & PS_S2o_2 \\
13 & Outlet of compressor at $90^{\circ}$ & PS_o_1 \\
14 & Outlet of compressor at $180^{\circ}$ & PS_o_2 \\
\hline
\end{tabular}

that on the low-speed compressor test bench. Table 2 presents the location of the measuring point. The measured parameters are the difference values between the local static pressure and the atmospheric pressure. The arrangement of the sensors and the measuring points of the high-speed axial compressor are presented in Figures 5 and 6, respectively.

\section{Results and Discussion}

\subsection{Two-Stage Low-Speed Axial Compressor}

4.1.1. Harmonic Fourier Mean Amplitude Analysis. When the compressor operates at a working point close to the stability boundary, it can enter the rotating stall state when the valve opening was shut down. Total pressure change due to the instability was obtained by the dynamic total pressure measurement. The modal wave was a small amplitude prestall disturbance. To reduce the influence of the wake interference, the measuring points were arranged at the inlet of the compressor. The dynamic total pressure signal of the two-stage low-speed axial compressor with uniform inlet flow is shown in Figure 7, and the Fourier analysis of the total pressure signal is presented in Figure 8 . With a rotational speed of $1200 \mathrm{r} / \mathrm{min}$, the compressor entered the rotating stall state at $8.51 \mathrm{~s}$. In the fully developed stage of the stall cell, there was only one stall cell in the whole passage of the compressor, and the characteristic frequency of the stall cell was $5.6 \mathrm{~Hz}$. The harmonic Fourier analysis was carried out based on the signals provided by six dynamic measuring points (Figure 9). The maximum amplitudes of the first-order harmonic were taken as the prediction indicator of compressor instability. $0.25 \mathrm{~s}, 0.5 \mathrm{~s}$, and $1.0 \mathrm{~s}$ were chosen as the time window, and $1100 \mathrm{~Pa}$ was taken as the warning threshold. Under all time windows, the compressor instability was predicted at $8.32 \mathrm{~s}$. The harmonic Fourier maximum amplitude analysis was not suitable in this compressor as there was little difference between the prediction time of the three-time windows. Instead, the harmonic Fourier mean amplitude analysis was applied.

Many factors could lead to the instantaneous change of the pressure signal such as the pressure distortion caused by the wake of the separation zone of cones, lip, strut, and prominence in the inlet. The random turbulence caused by the boundary layer separation made the pressure parameter fluctuate with time and space. The maximum value was taken as the early warning signal to avoid misjudgment caused by the instantaneous change. In the present work, the mean value of the first-order harmonic amplitude in a period of time was taken as the prediction indicator of compressor instability, and $550 \mathrm{~Pa}$ was taken as the early warning threshold value. It was found that the smaller the time window was, the earlier the compressor instability could be predicted. The compressor instability was predicted at $8.32 \mathrm{~s}$ when the time window was set as $0.125 \mathrm{~s}$, whereas the compressor instability was predicted at $8.53 \mathrm{~s}$ with a time window of $0.5 \mathrm{~s}$ (Figure 10). The difference in the prediction time indicated the measuring signal amplitude versus time. It is noticeable that the fluctuation of the pressure signal near the warning threshold could lead to the misjudgment of the stall. However, the fluctuation range was relatively small, and the last entry above the threshold in the $0.125 \mathrm{~s}$ time window case was still the earliest among others. The instability state was predicted in advance by using $0.125 \mathrm{~s}$ as the time window and adopting the mean value of the first-order harmonic amplitude as the early warning parameter in this low-speed compressor.

The prediction results of the mean amplitude of the firstorder signals and the second-order harmonic signals were compared (Figure 11). When the time window and the early warning threshold were set as $0.125 \mathrm{~s}$ and $550 \mathrm{~Pa}$, respectively, the first-order signal predicted the compressor instability earlier than the second-order signal, which predicted the compressor instability at $8.51 \mathrm{~s}$.

4.1.2. Heterotopic Variance Analysis. Heterotopic variance analysis was carried out, and the dynamic total pressure of measuring points 1 and 4 was analyzed (Figure 12). Onesixteenth of the sampling frequency $(1 / 16 \mathrm{~s})$ was chosen as the time window. The difference between values of $\sigma_{1}^{2}$ and $\sigma_{2}^{2}$ was not large. When $10000 \mathrm{~Pa}^{2}$ was set as the stability threshold, $\sigma_{1}{ }^{2}$ predicted the compressor instability earlier. The compressor entered the instability state at $8.16 \mathrm{~s}$, when $\sigma_{1}^{2}$ was equal to $10021 \mathrm{~Pa}^{2}$ and $\sigma_{2}^{2}$ was equal to $5814 \mathrm{~Pa}^{2}$.

The instability prediction results were different among the combination of measuring points along the circumference. The machining error such as the incomplete symmetry of the casing and the blade along the circumference and the quality difference between the sensors and the probes might lead to the difference. The heterotopic variance analysis of the five combinations of measuring points 1 and 2, 3, 4, 5, and 6 was carried out, respectively (Figure 13). Due to the circumference difference of $120^{\circ}$, the stall cell does not appear as a strict sinusoidal form. The selection of an appropriate combination of circumferential measuring points was conducive to determining whether the compressor instability 


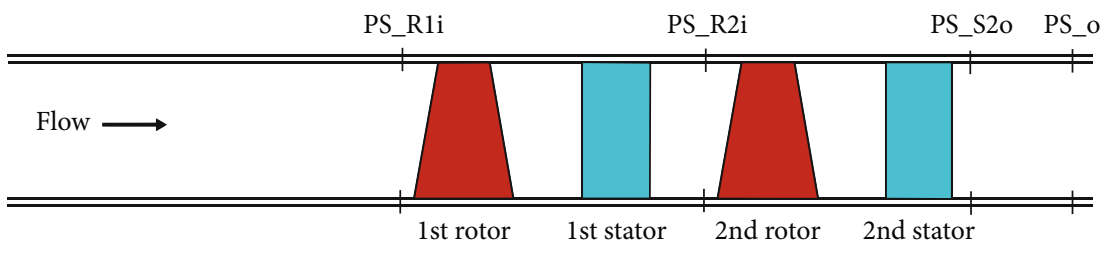

FIGURE 5: Sensor arrangement sketch of the high-speed axial compressor.
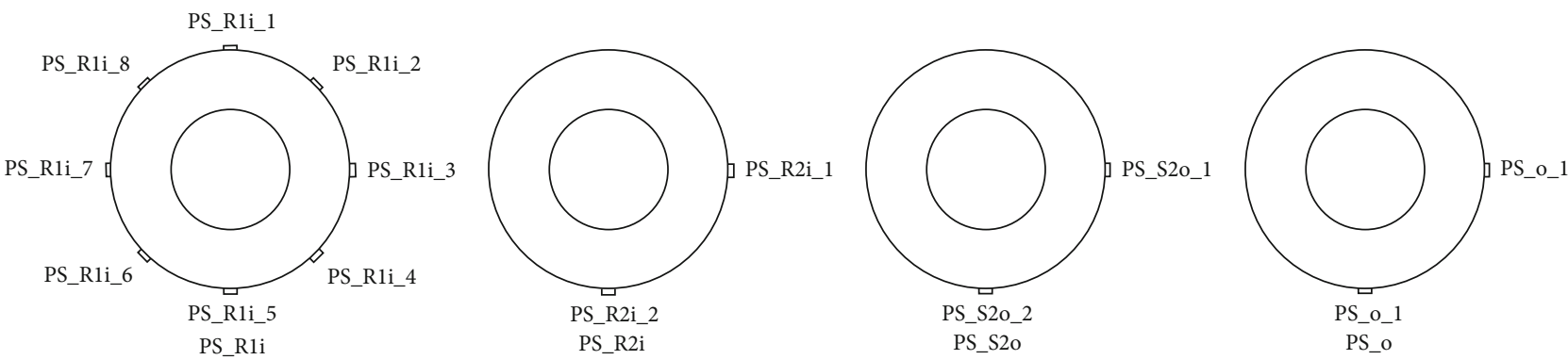

FIgURE 6: Measurement point sketch of the high-speed axial compressor.

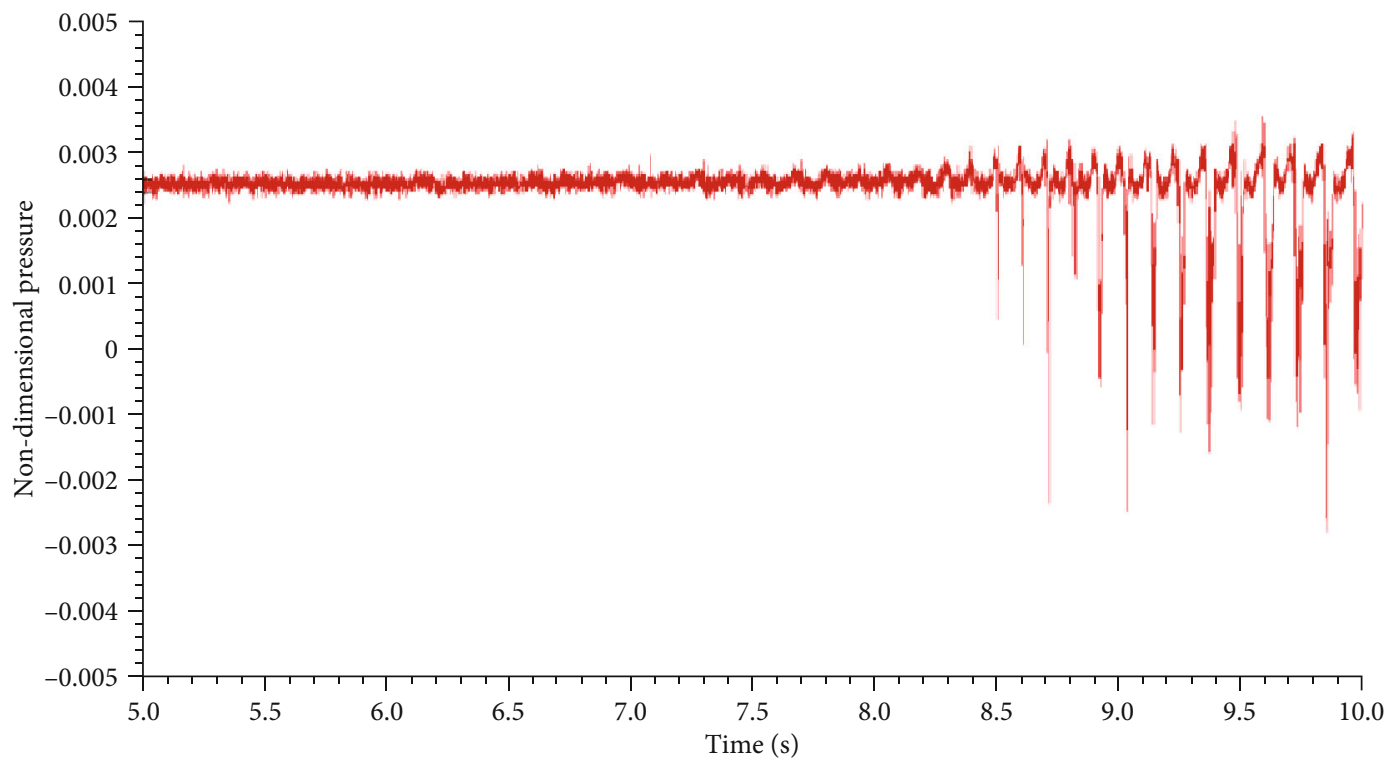

FIGURE 7: Time history of the dynamic total pressure output during the stall inception of the low-speed compressor.

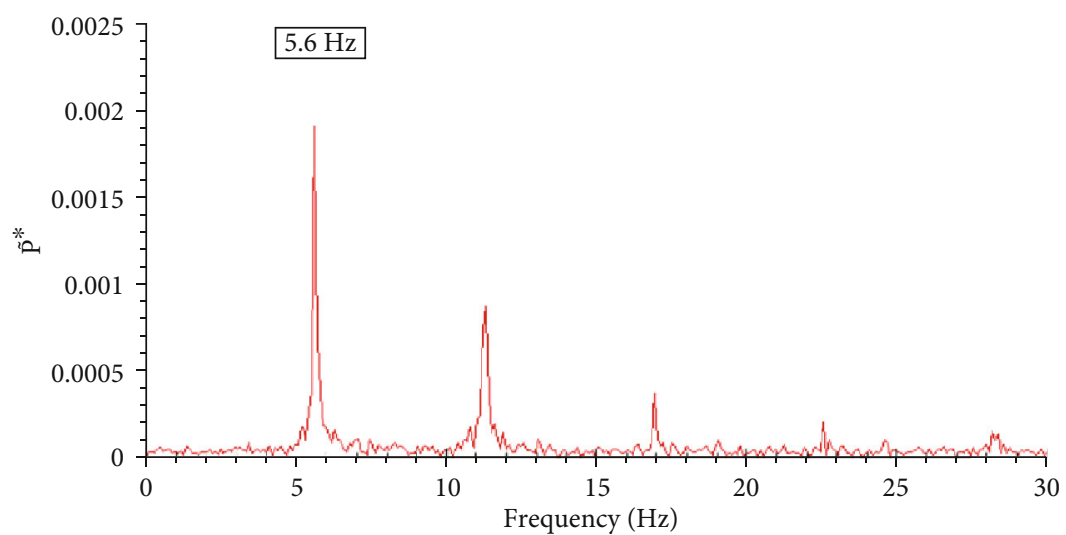

Figure 8: Spectrum analysis of the total pressure signal during the fully developed phase of the stall cell. 


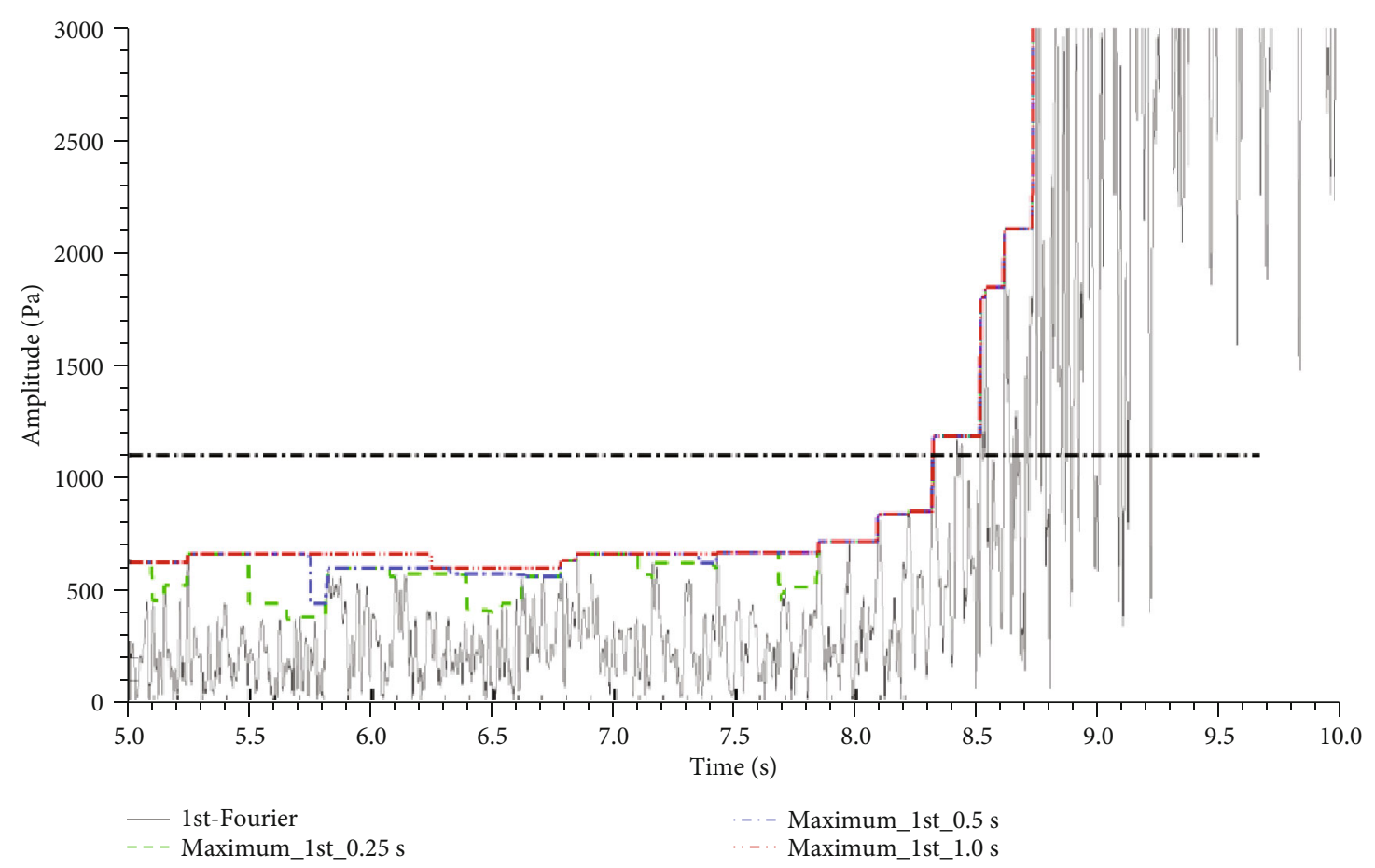

FIGURE 9: The maximum amplitude of the first-order harmonic of the total pressure during the stall inception.

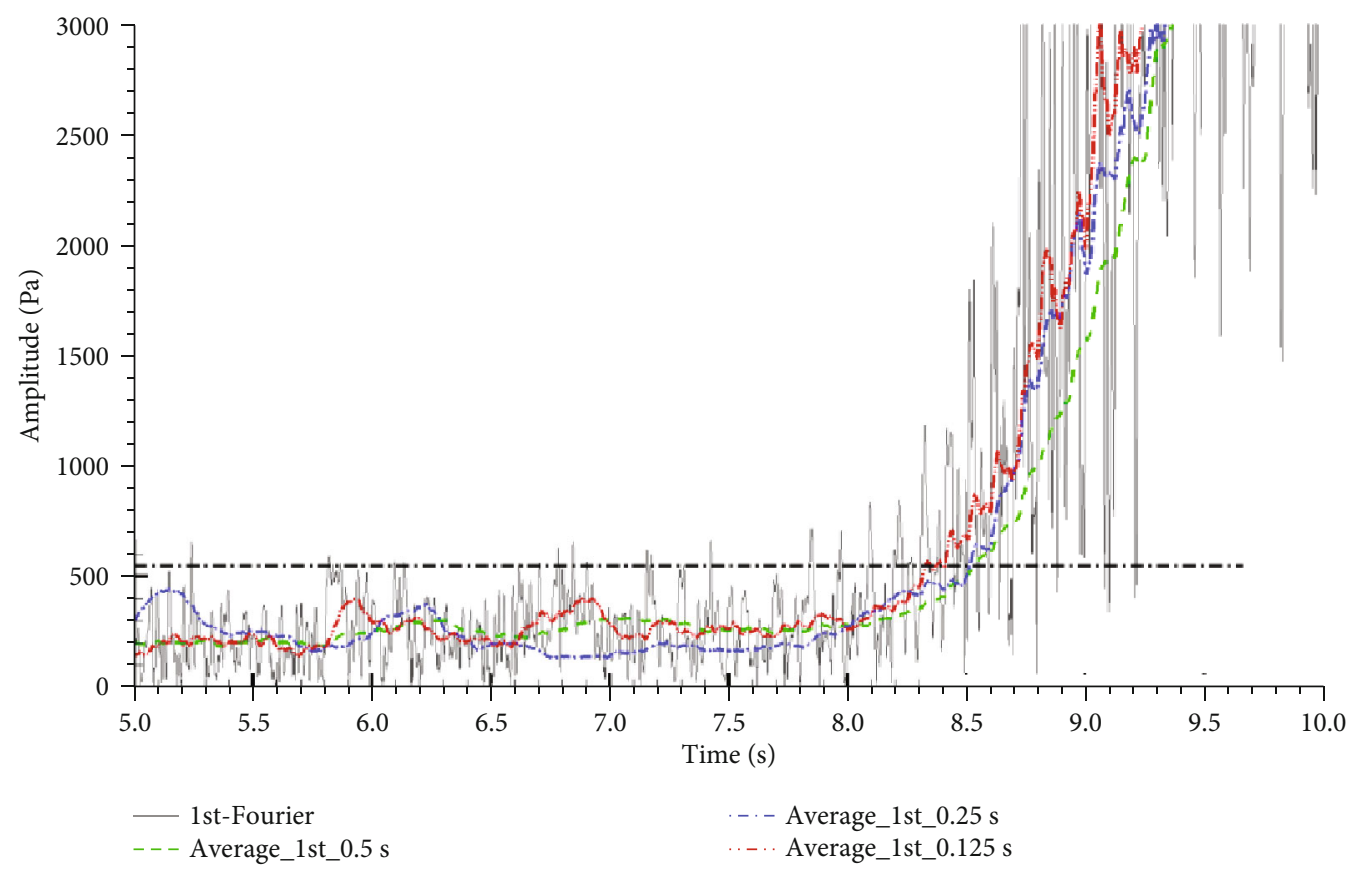

FiguRE 10: Mean amplitude of the first-order harmonic of the total pressure during the stall inception. 


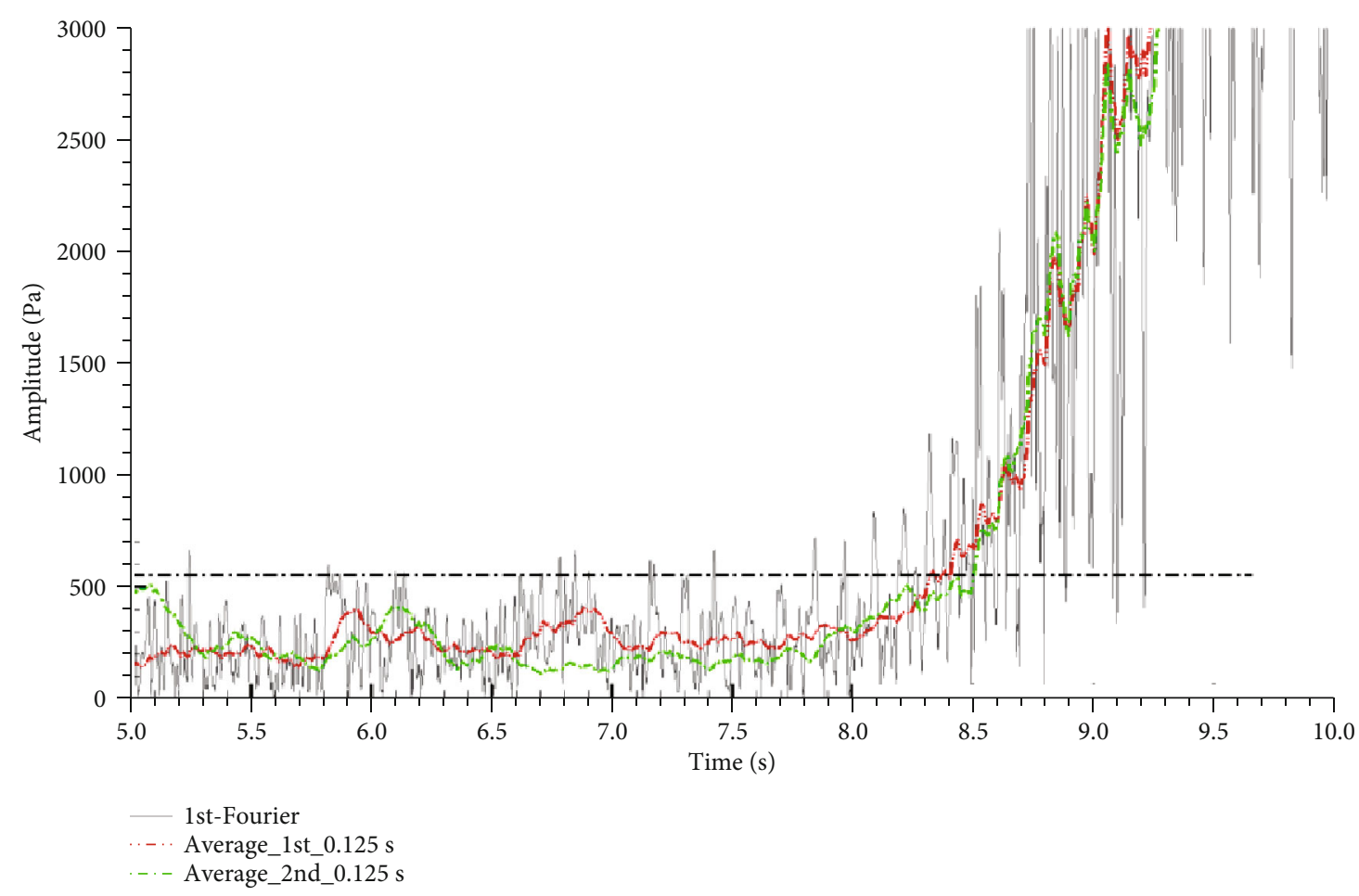

FIgURE 11: Mean amplitude of the first- and second-order harmonic of the total pressure signal during the stall inception.

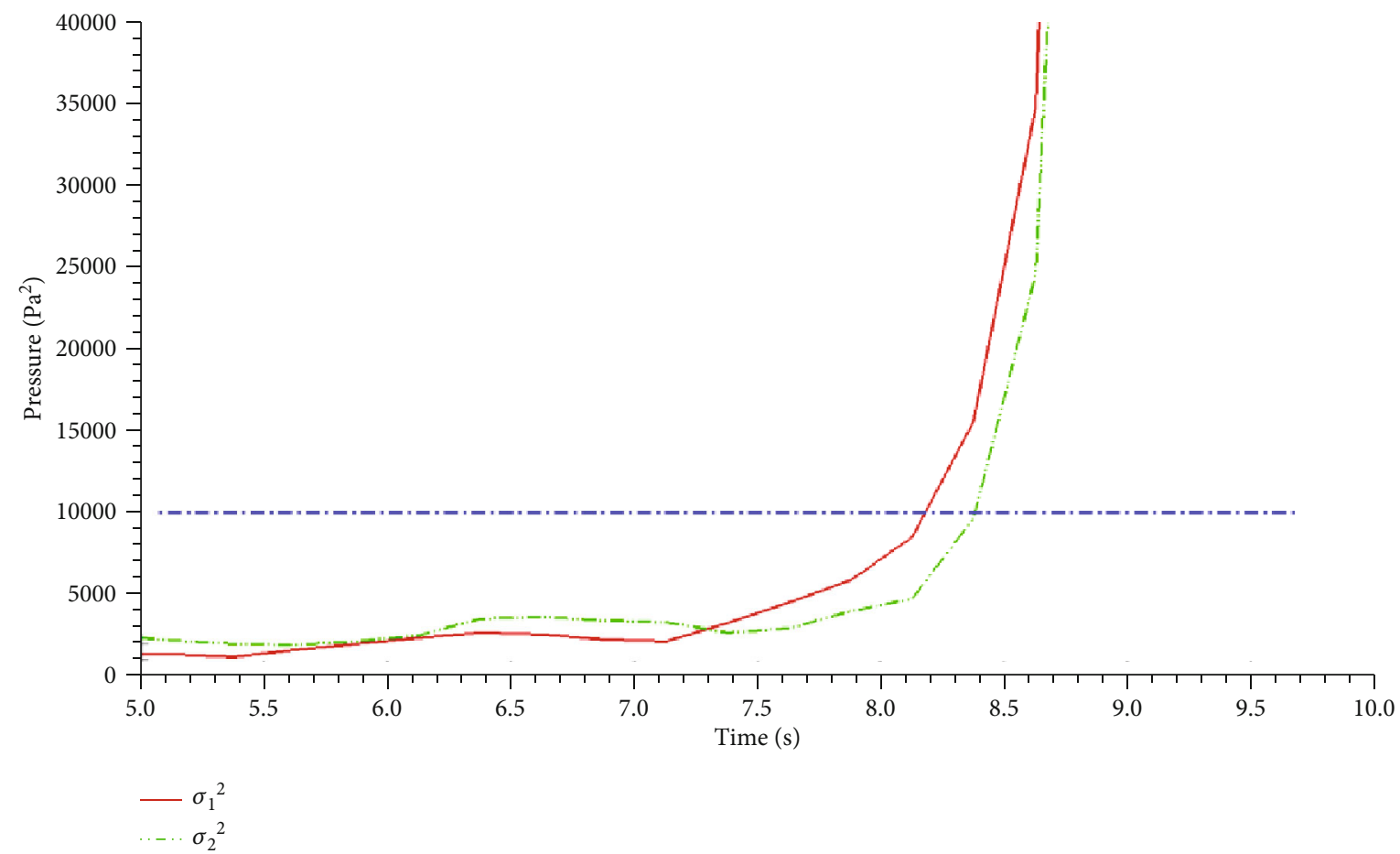

Figure 12: Analysis results of the heterotopic variance using measuring points of $0^{\circ}$ and $180^{\circ}$ in the circumferential direction. 


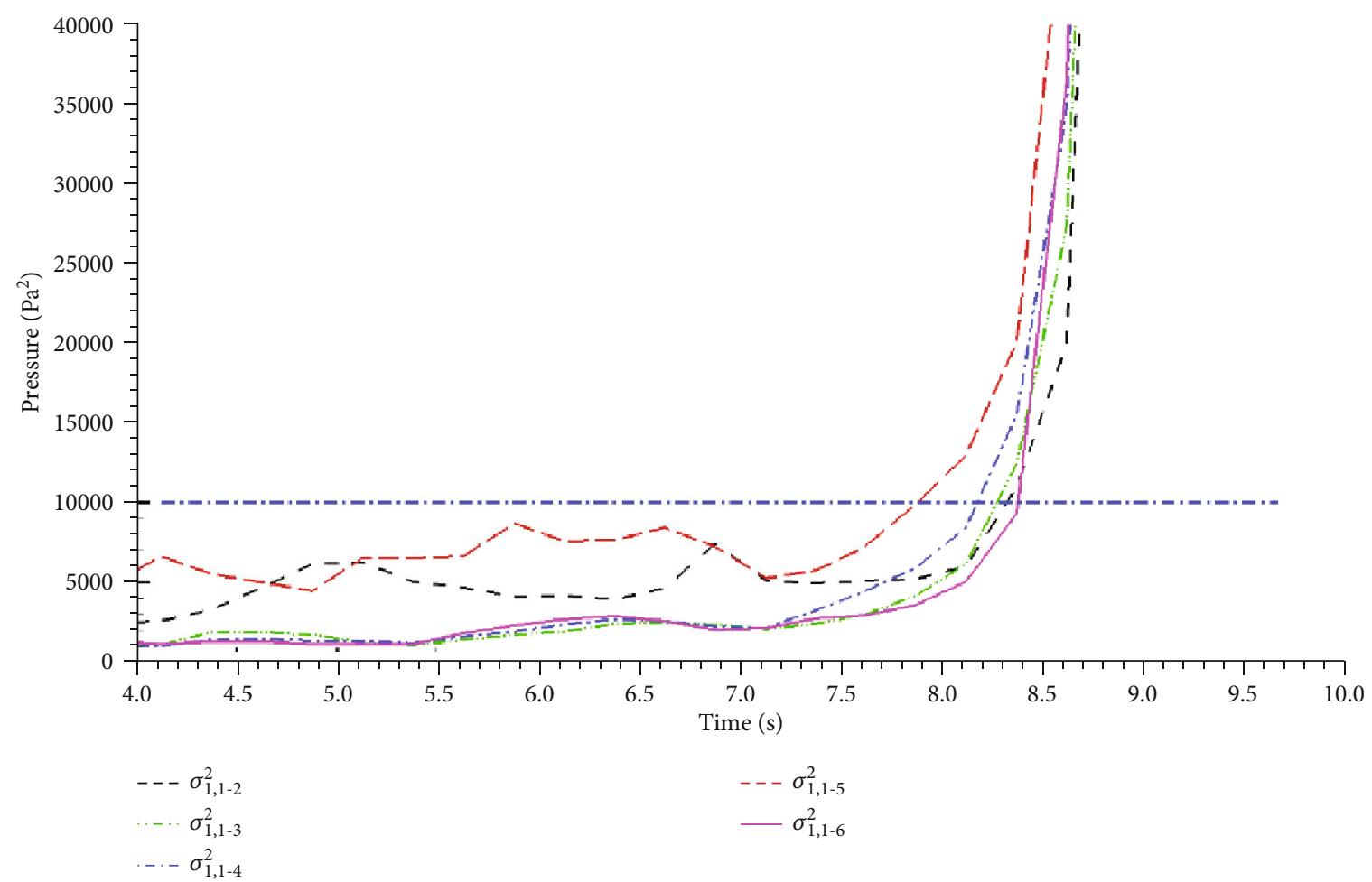

FIGURE 13: Analysis results of the heterotopic variance with different combinations of measuring points.

occurred as early as possible. For the low-speed compressor, the combination of points 1 and 5 was more appropriate. When $\sigma_{1,1-2}^{2}$ was set as the aerodynamic instability indicator and the early warning threshold was set as $10000 \mathrm{~Pa}^{2}$, the compressor instability occurred at $7.88 \mathrm{~s}$.

4.2. Two-Stage High-Speed Axial Compressor. High-speed axial compressors are easily damaged when working at the instability state; hence, the compressor needs to be adjusted quickly to exit the instability state when instability occurs. The static pressure at different positions during the dynamic instability process of the compressor is presented in Figure 14. Static pressure signals detected by measuring points at different circumferential positions at the inlet of the first rotor were almost the same. The same situation occurred at the outlet of the second rotor, the outlet of the second stator, and the outlet of the compressor. Meanwhile, different pressure pulsations at different axial positions indicate that the airflow pulsated along the axis of the compressor and the compressor was working at the surge state. It is noticeable that although the two-stage high-speed axial compressor was in the surge state, there are some differences in the dynamic signals measured at different circumferential positions. Earlier detection of compressor instability can be achieved by an appropriate measurement layout. The inlet static pressure at PS_R1i_1 gradually rose from $5.393 \mathrm{~s}$, indicating that from this time, the compressor entered the surge state. The static pressure increased slowly at other positions of the inlet, for example, PS_R1i_2 starts from $5.486 \mathrm{~s}$. The time when the static pressure of the two measuring points at the inlet of the second stage rotor increased was also not the same. PS_R2i_1 began to increase at $5.487 \mathrm{~s}$, whereas PS_R2i_2 began to increase at $5.454 \mathrm{~s}$. Both the static pressure at the second stage stator outlet and the compressor outlet began to increase at $5.487 \mathrm{~s}$.

4.2.1. Harmonic Fourier Mean Amplitude Analysis. According to the previous research results, the prestall disturbance (the modal wave or the spike) can be detected by arranging the dynamic pressure sensor at the compressor inlet. The harmonic analysis of the dynamic static pressure in the instability process of the two-stage high-speed axial compressor was carried out (Figure 15). The mean value of the first-order harmonic amplitude was taken as the instability prediction parameter. The warning threshold value was $20 \mathrm{kPa}$. When the time window was set as $0.08 \mathrm{~s}, 0.04 \mathrm{~s}$, and $0.01 \mathrm{~s}$, the compressor aerodynamic instability was predicted at $5.411 \mathrm{~s}, 5.399 \mathrm{~s}$, and $5.395 \mathrm{~s}$, respectively, indicating that earlier prediction can be achieved by adopting smaller time windows.

Figure 16 displays the change of the second-order component under the harmonic Fourier analysis. The mean amplitude of the second-order harmonic component was larger than that of the first order. The mean value of the second-order harmonic amplitude was still used as the instability prediction parameter. When the time window was set as $0.08 \mathrm{~s}, 0.04 \mathrm{~s}$, and $0.01 \mathrm{~s}$, the compressor aerodynamic instability was predicted at $5.406 \mathrm{~s}, 5.398 \mathrm{~s}$, and $5.395 \mathrm{~s}$, respectively, indicating that the second-order analysis was more suitable for the aerodynamic instability detection in the high-speed axial compressor. 

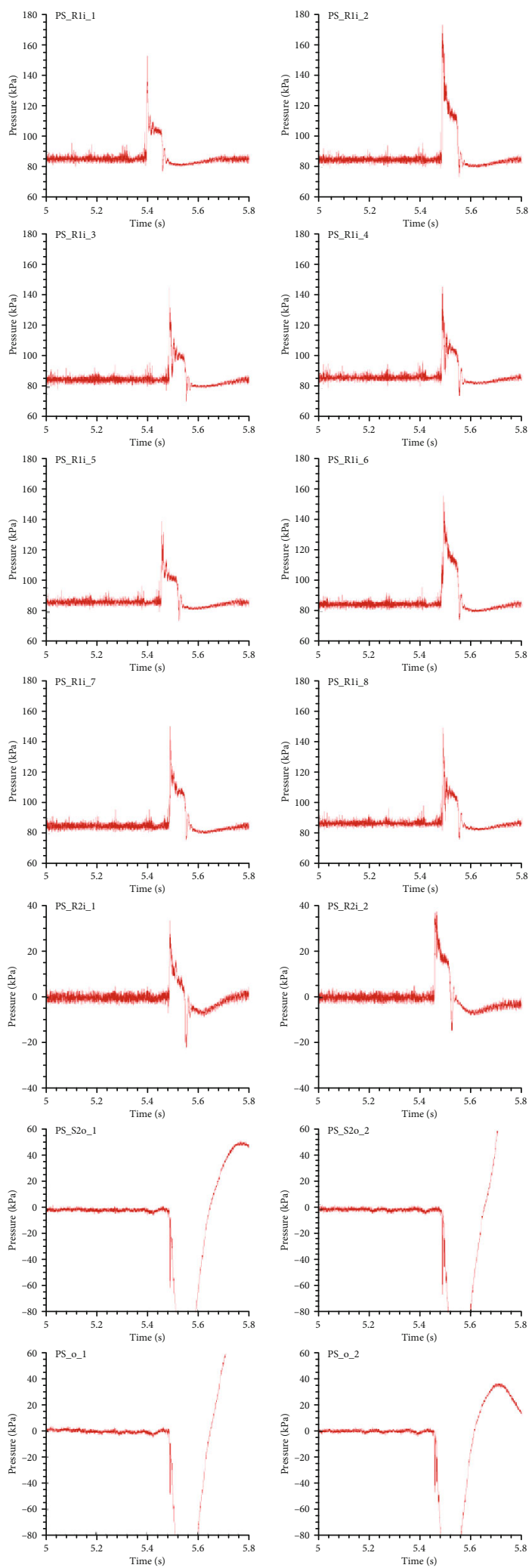

FIGURE 14: Static pressure changes at different positions in the dynamic instability process of the compressor. 


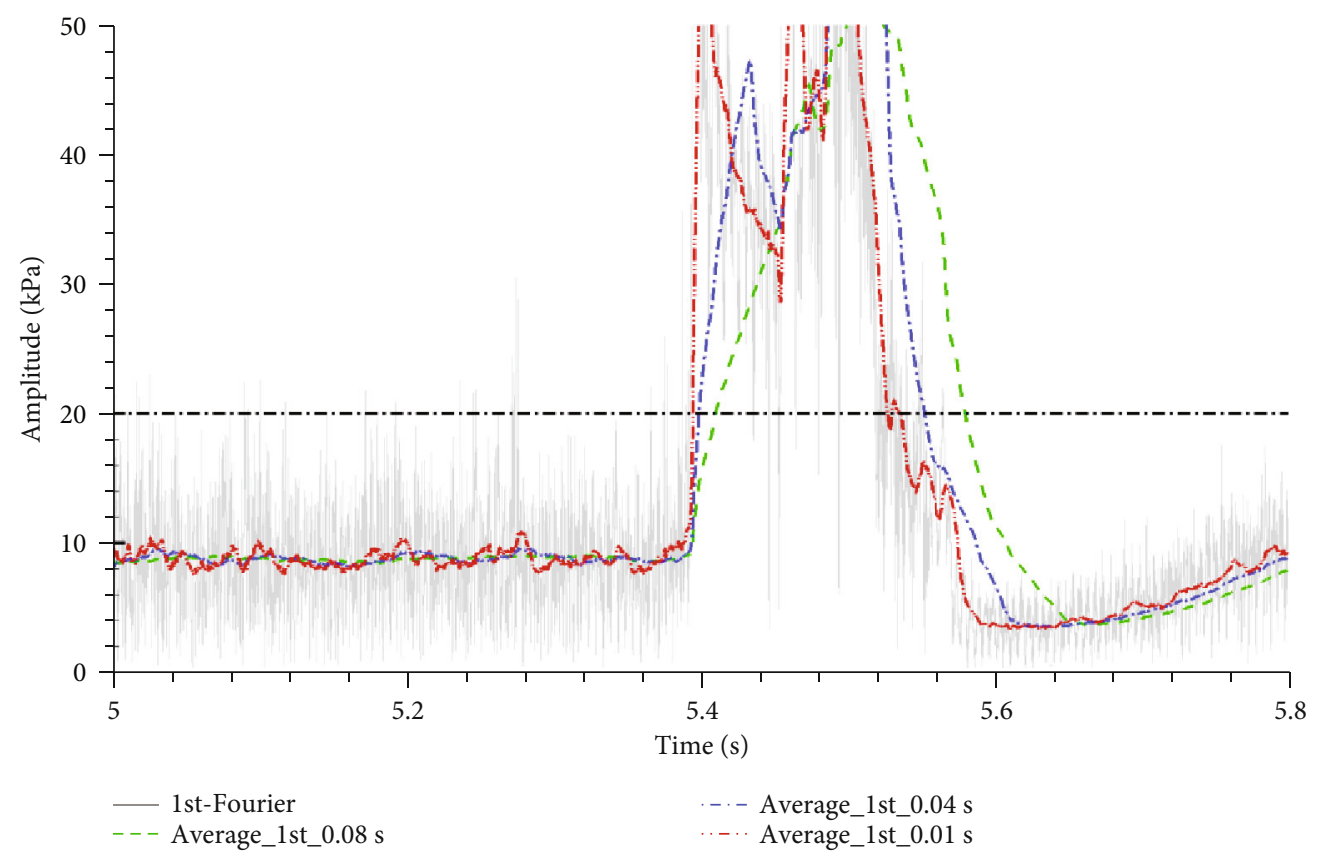

FIGURE 15: First-order harmonic analysis results of the inlet static pressure during the instability process of the compressor.

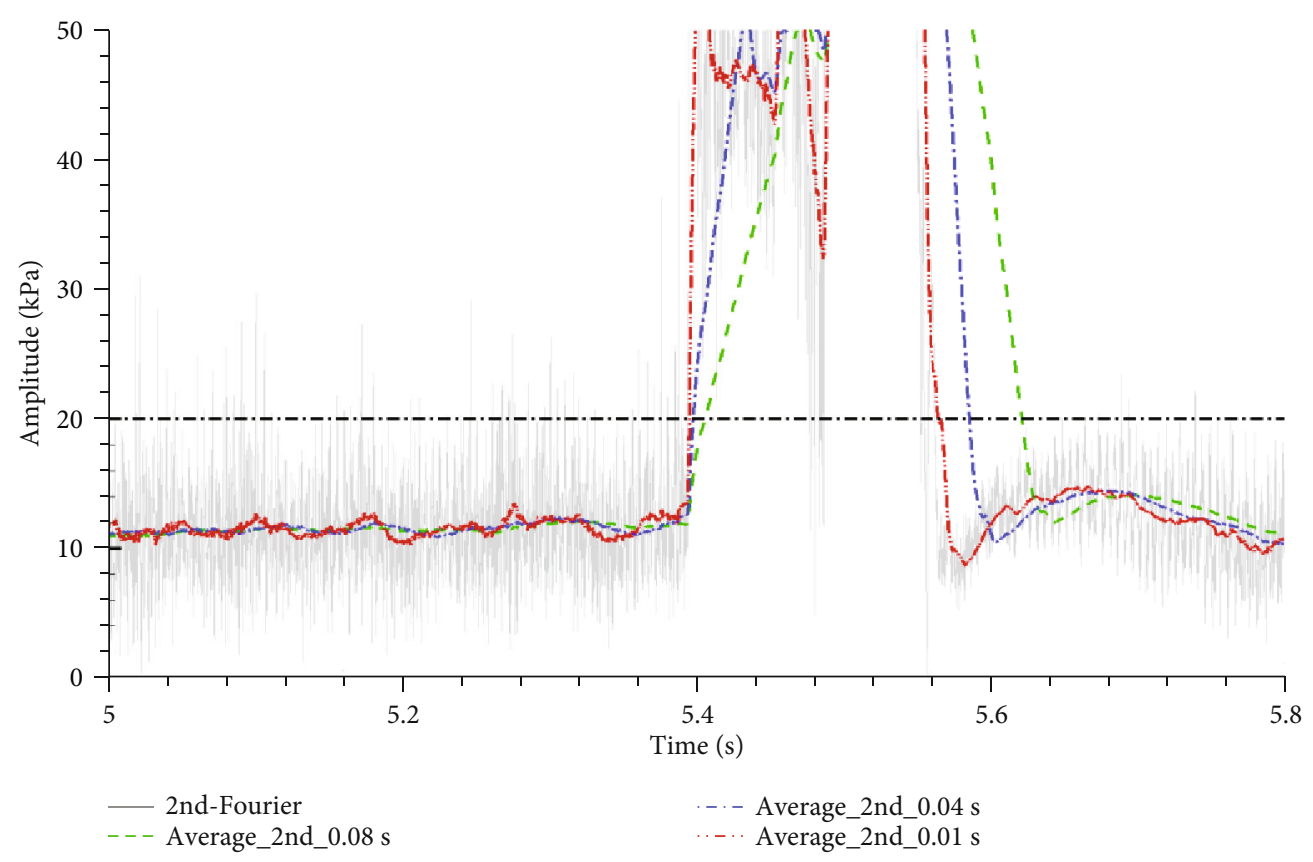

FIgURE 16: Second-order harmonic analysis results of the inlet static pressure.

4.2.2. Heterotopic Variance Analysis. The static pressure at the inlet of the compressor was processed under the heterotopic variance analysis method. Measuring point 1 was combined with points $2,3,4,5,6,7$, and 8 , respectively, and $20 \mathrm{kPa}$ was taken as the early warning threshold value. The instability onset time under different measuring point combinations was compared (Figure 17). When the combi- nation of points 1 and 2 was adopted, the compressor instability started at $5.380 \mathrm{~s}$. While points 1 and 7 are combined, the compressor entered an instability state at $5.386 \mathrm{~s}$. If $\sigma_{2}^{2}$ was used to determine the stability, the compressor entered an instability state at $5.384 \mathrm{~s}$. Therefore, for the high-speed axial compressor, $\sigma_{1}^{2}$ was more favorable to detect the compressor instability. 

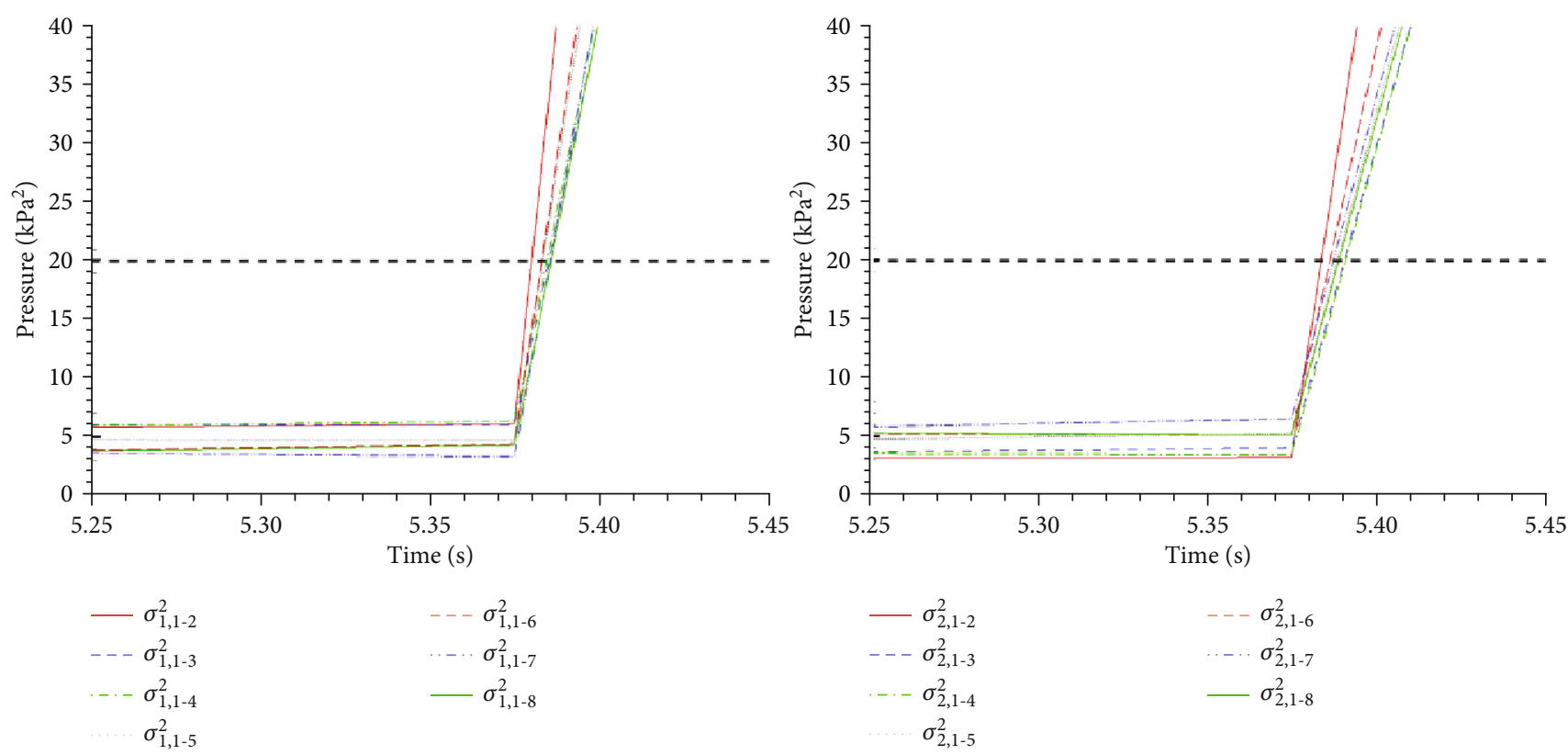

FIGURE 17: Results of the heterotopic variance analysis of the inlet static pressure during compressor instability.
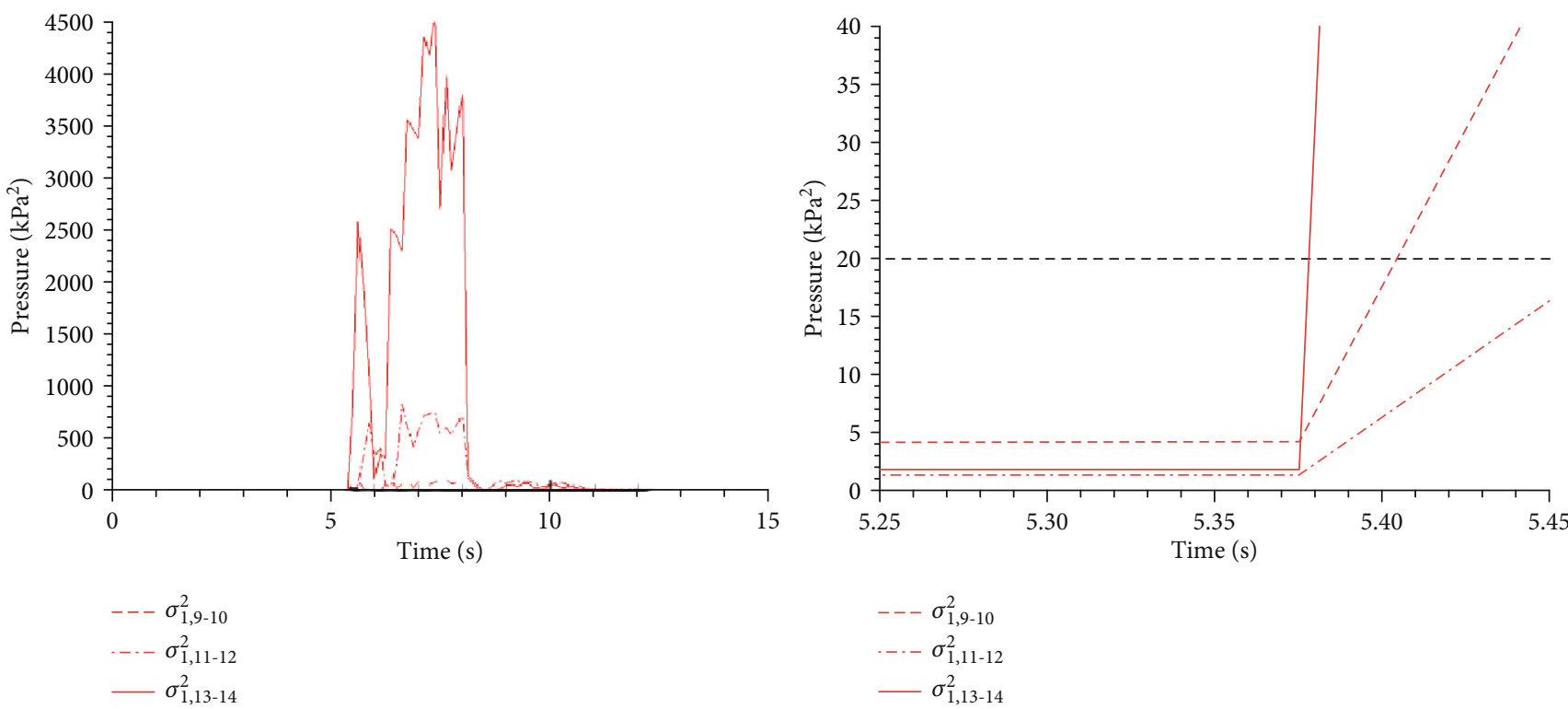

FIGURE 18: Variation of $\sigma_{1}^{2}$ at R2 inlet, S2 outlet, and compressor outlet.

According to the calculation formula of the two parameters, $\sigma_{1}^{2}$ and $\sigma_{2}^{2}$, under the heterotopic variance analysis method, $\sigma_{2}^{2}$ was larger than $\sigma_{1}^{2}$ when the compressor was at the surge state. The development of the surge which was generated first at the inlet or the outlet of the compressor was a process of axial transmission. Therefore, the layout of the measuring points also affected the compressor instability detection results. Considering that most of the practical applications of the aeroengine adopted the detection result of the pressure signal at the compressor outlet, the measuring section is arranged at the compres- sor outlet in the present work. Variation of $\sigma_{1}^{2}$ and $\sigma_{2}^{2}$ during the compressor instability process is presented in Figures 18 and 19, respectively. When adopting the combination of two static pressure parameters at the compressor outlet, the compressor aerodynamic instability could be detected the earliest. When taking $20 \mathrm{kPa}$ as the warning threshold, the compressor instability started at $5.378 \mathrm{~s}$. While using $\sigma_{2,13-14}^{2}$, the compressor lost stability at $5.377 \mathrm{~s}$. Thus, it was more preferable to arranged the measuring points at the compressor outlet to detect the aerodynamic instability. 

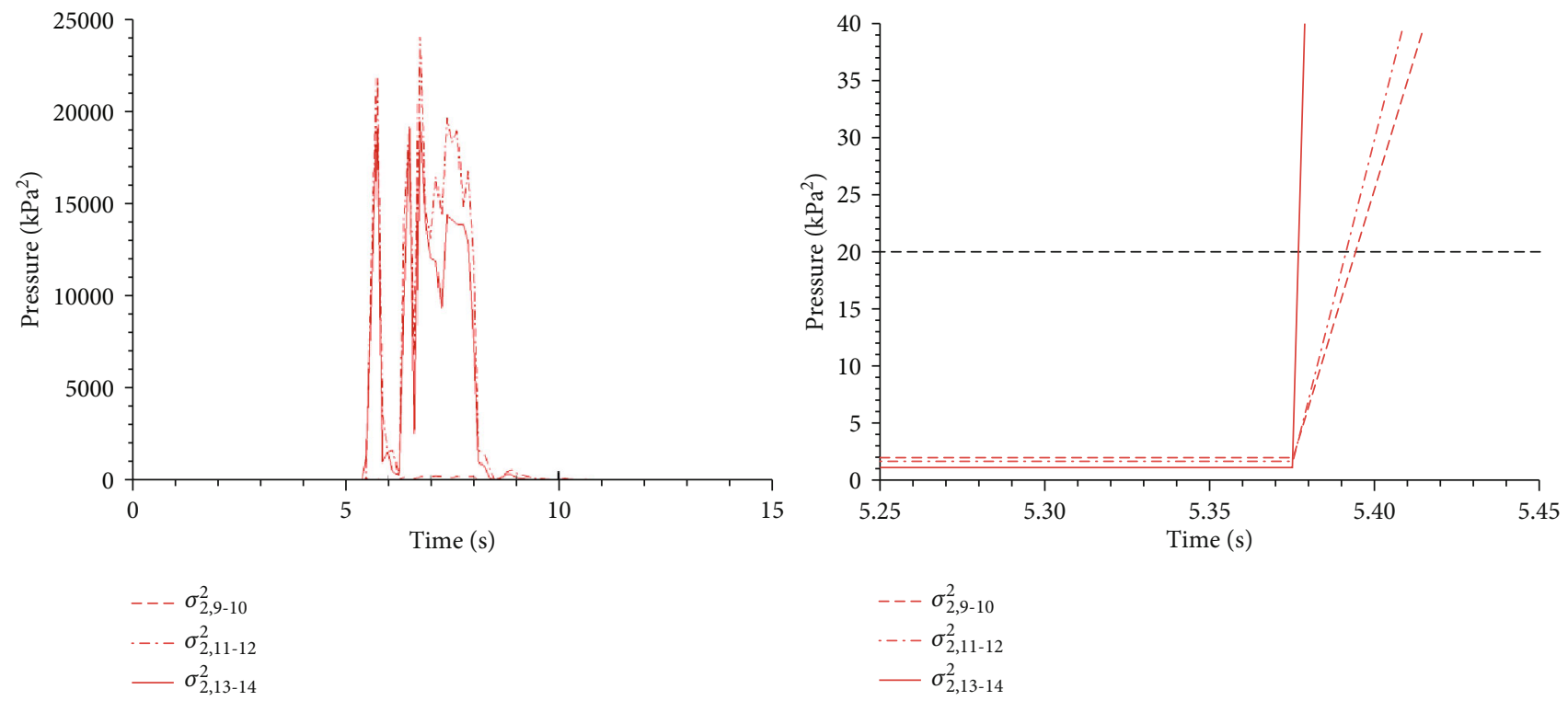

FIgURE 19: Variation of $\sigma_{2}^{2}$ at R2 inlet, S2 outlet, and compressor outlet.

\section{Conclusions}

In the present work, early and accurate detection of the aerodynamic instability compressor was realized on a multistage axial compressor under two newly developed methods: the harmonic Fourier mean amplitude analysis method and the heterotopic variance analysis method. The harmonic Fourier mean amplitude analysis method can avoid the instability misjudgment due to the sudden change of pressure signal caused by external interference during the operation of the compressor. The method requires at least three measuring points arranged along the circumference, and it is suitable to predict the instability state of the rotating stall. The heterotopic variance analysis method has fewer requirements for the number of circumferential measuring points, and it can identify the type of aerodynamic instability (the rotating stall or the surge).

When the harmonic Fourier mean amplitude analysis method is used to predict the compressor aerodynamic instability, the selection of the time window matters. The pressure fluctuation generates when the time window is too small, whereas the early warning of the compressor instability is delayed when the time window is too large. Early warning with first-order or second-order components needs to be specific. There is only one stall group in the low-speed axial compressor studied in the present work; thus, the firstorder harmonic analysis is suitable. When the aerodynamic instability occurs in the high-speed axial compressor, the surge process is accompanied by the rotating stall. The second-order harmonic analysis is more appropriate because dynamic pressure signals were relatively complex in this case.

The heterotopic variance analysis method is more suitable for the detection of compressor aerodynamic instability than the harmonic Fourier average amplitude analysis method because it requires fewer circumferential measuring points. The compressor aerodynamic instability can be detected earlier by appropriate measurement arrangement. For both axial compressors studied in this paper, the heterotopic variance analysis method can predict the instability earlier than the harmonic Fourier mean amplitude analysis method. The prediction in the low-speed compressor and the high-speed compressor is advanced by $0.44 \mathrm{~s}$ (9.6 rotor rotation cycles) and $0.018 \mathrm{~s}$ (5.4 rotor rotation cycles), respectively.

The layout of the measuring point influences the result of the aerodynamic instability detection. An appropriate layout of measuring points helps to detect the aerodynamic instability of the compressor earlier. In the present work, for both low-speed and high-speed compressors, dynamic pressure sensors are arranged along the circumferential direction at the compressor inlet section (about one chord length upstream of the compressor) to measure the dynamic signal during the dynamic stall process of the compressor and determine the type of the stall precursor through signal analysis. The advantage of this method is that the measured signals are only affected by the rotor potential disturbance before the stall cell is generated, and the prestall disturbance can be observed more obviously in the dynamic stall process. If the starting position of the stall can be determined in the first place, and then, the signal detected by circumferential measurement points arranged on this cross-section is analyzed through harmonic Fourier mean amplitude analysis or heterotopic variance analysis, the instability prediction is going to be much earlier. For the high-speed axial compressor studied in this paper, the surge signal develops from the outlet to the inlet, and the aerodynamic instability of the compressor can be predicted earlier by arranging the measuring point at the compressor outlet.

Machining error and installation error also have a negative effect on the early warning results under the heterotopic variance analysis method. Since the machining error and the installation error have randomness, researchers can only find 
out the right circumferential detection position by trying. Future research of evaluating the effect of machining and installation errors on heterotopic variance analysis will be helpful to figure out to what degree can the location of the circumferential sensor affect the prediction results.

\section{Data Availability}

The data used to support the findings of this study have not been made available because it cannot be released.

\section{Conflicts of Interest}

The authors declare that they have no conflict of interest.

\section{Authors' Contributions}

B.T., X.Z., and J.H. designed the experimental scheme and carried out the low-speed axial compressor experimental research. B.X. and M.Z. carried out the high-speed axial compressor experimental research. B.T. develops the harmonic Fourier mean amplitude analysis method and heterotopic variance analysis method and wrote the paper.

\section{Acknowledgments}

This study was supported by the National Science and Technology Major Project (2017-II-0004-0017).

\section{References}

[1] A. D. Jackson, "Stall cell development in an axial compressor," Journal of Turbomachinery, vol. 109, no. 4, pp. 492-498, 1987.

[2] N. M. McDougall, N. A. Cumpsty, and T. P. Hynes, "Stall inception in axial compressors," Journal of Turbomachinery, vol. 112, no. 1, pp. 116-123, 1990.

[3] V. H. Garnier, A. H. Epstein, and E. M. Greitzer, "Rotating waves as a stall indication in axial compressors," Journal of Turbomachinery, vol. 115, pp. 290-302, 1991.

[4] I. J. Day, "Stall inception in axial flow compressors," Journal of Turbomachinery, vol. 115, no. 1, pp. 1-9, 1993.

[5] T. R. Camp and I. J. Day, "1997 Best Paper Award-Turbomachinery Committee: a study of spike and modal stall phenomena in a low-speed axial compressor," Journal of Turbomachinery, vol. 120, no. 3, pp. 393-401, 1998.

[6] I. J. Day, T. Breuer, J. Escuret, M. Cherrett, and A. Wilson, "Stall inception and the prospects for active control in four high-speed compressors," Journal of Turbomachinery, vol. 121, no. 1, pp. 18-27, 1999.

[7] M. Tryfonidis, O. Etchevers, J. D. Paduano, and G. J. Hendricks, "Pre-stall behavior of several high-speed compressors," Journal of Turbomachinery, vol. 17, pp. 62-80, 1995.

[8] B. F. Tu, J. Hu, and Y. Zhao, "3D unsteady computation of stall inception in axial compressors," in Volume 7: Turbomachinery, Parts A, B, and C, pp. 2363-2371, Glasgow, UK, 2010.

[9] Silkowski, "Measurement of rotor stalling in a matched and a mismatched multistage compressor," GTL Report No 221, Gas Turbine Laboratory, 1995.

[10] L. Liu, J. C. Li, X. Nan, and F. Lin, “The stall inceptions in an axial compressor with single circumferential groove casing treatment at different axial locations," Aerospace Science and Technology, vol. 59, pp. 145-154, 2016.

[11] J. C. Li, S. Geng, J. du, H. Zhang, and C. Nie, "Circumferentially propagating characteristic dominated by unsteady tip leakage flow in axial flow compressors," Aerospace Science and Technology, vol. 85, pp. 529-543, 2019.

[12] J. C. Li, J. du, C. Q. Nie, and H. W. Zhang, "Review of tip air injection to improve stall margin in axial compressors," Progress in Aerospace Sciences, vol. 106, pp. 15-31, 2019.

[13] Y. Liu, J. C. Li, J. du, F. Li, and H. W. Zhang, “Application of fast wavelet analysis on early stall warning in axial compressors," Journal of Thermal Science, vol. 28, no. 5, pp. 837-849, 2019.

[14] Q. S. Li, T. Y. Pan, Z. P. Li, T. L. Sun, and Y. F. Gong, "Experimental study of compressor instability inception in a transonic axial flow compressor," in ASME Turbo expo 2014: turbine technical conference and exposition, pp. 16-20, Dusseldorf, Germany, 2014.

[15] Q. S. Li, T. Y. Pan, T. L. Sun, Z. P. Li, and Y. F. Gong, "Experimental investigations on instability evolution in a transonic compressor at different rotor speeds," Proceedings of the Institution of Mechanical Engineers, Part C: Journal of Mechanical Engineering Science, vol. 229, pp. 3378-3391, 2015.

[16] R. Rzadkowski, V. Gnesin, L. Kolodyazhnaya, and L. Kubitz, "Aeroelastic behaviour of a 3.5-stage aircraft compressor rotor blades following a bird strike," Journal of Vibration Engineering \& Technologies, vol. 6, no. 4, pp. 281-287, 2018.

[17] R. Rzadkowski, "Dynamic multi-stage analysis of a mistuned aircraft rotor with foreign object ingestion," Journal of Vibration Engineering \& Technologies, vol. 6, no. 5, pp. 339-355, 2018.

[18] M. M. Bright, H. K. Qammar, H. J. Weigl, and J. D. Paduano, "Stall precursor identification in high-speed compressor stages using chaotic time series analysis methods," Journal of Turbomachinery, vol. 119, no. 3, pp. 491-499, 1997.

[19] T. Nakano and H. Kodama, "Numerical and experimental investigation of instability inception in a high-speed axialflow compressor using chaos theory," in 38th AIAA/ASME/SAE/ASEE Joint Propulsion Conference and Exhibit, pp. 1-8, Indianapolis, IN, USA, 2002.

[20] Z. P. Li, P. Zhang, and Q. S. Li, "Model description of rotating stall boundary in low-speed axial compressor," Journal of Aerospace Power, vol. 32, pp. 519-527, 2017.

[21] P. Lin, C. Wang, and M. Wang, "Bifurcation predication in axial compressors with nonuniform inflow via deterministic learning," International Journal of Bifurcation and Chaos, vol. 27, no. 10, p. 1750159, 2017.

[22] E. Munari, G. D'Elia, M. Morini, E. Mucchi, M. Pinelli, and P. R. Spina, "Experimental investigation of vibrational and acoustic phenomena for detecting the stall and surge of a multistage compressor," in ASME Turbo Expo 2017: Turbomachinery technical conference and exposition, pp. 26-30, Charlotte, North Carolina, USA, 2017. 